\title{
ARQUETIPOLOGIA E EDUCAÇÃO: Considerações para uma pedagogia do imaginário
}

ARCHÉTYPOLOGIE ET ÉDUCATION: Considérations pour une pédagogie de l'imaginaire

William Gustavo Machado. ${ }^{1}$

\section{http://dx.doi.org/10.52641/cadcaj.v6i4.542}

RESUMO: Através de um breve estudo acerca da teoria do imaginário do antropólogo francês Gilbert Durand, o presente artigo procura atentar para reflexões na área da Educação que digam respeito a essas propriedades tão humanas e tão negligenciadas pelas pedagogias dominantes: a função fantástica, a imaginação, o imaginário. De início procura-se elucidar acerca do pressuposto epistemológico durandiano: não há pré-determinações que deem conta de explicar o ser humano, não há tipologias; por outro lado, pelos estudos de uma arquetipologia que se mostra como um estudo do que é universal no ser humano enquanto espécie (os arquétipos), pode-se ter uma aproximação de e para práticas pedagógicas que percebam o humano como ele simplesmente se manifesta. Após isso há uma introdução à teoria de Durand e enfim algumas considerações reflexivas ligadas à Educação.

Palavras-Chave: Imaginário. Educação. Gilbert Durand.

RÉSUMÉ: A travers une brève étude sur la théorie de l'imaginaire de l'anthropologue français Gilbert Durand, cet article cherche à porter attention aux réflexions dans le domaine de l'éducation qui concernent cettes propriétés si humaines et si négligées par les pédagogies dominantes: la fonction fantastique, l'imagination, l'imaginaire. Dans un premier temps, nous essayons d'élucider l'hypothèse épistémologique durandienne: il n'y a pas de pré-déterminations qui peuvent expliquer l'être humain, il n'y a pas de typologies; d'autre part, à travers l'étude d'une archétypologie qui se manifeste comme une étude de ce qui est universel dans l'être humain en tant qu'espèce (les archétypes), on peut avoir une approche de et pour des pratiques pédagogiques qui perçoivent l'humain tel qu'il est simplement se manifeste. Après cela, il y a une introduction à la théorie de Durand et enfin quelques réflexions liées à l'éducation.

\footnotetext{
${ }^{1}$ Graduando em Filosofia (Bacharelado) pelo Centro Universitário UNINTER, músico e professor de música. E-mail: wgmachado1991@gmail.com
} 
Mots clés: Imaginaire. Éducation. Gilbert Durand.

\section{INTRODUÇÃO}

'Um bumanismo planetário não se pode fundar sobre a exclusiva conquista da ciência, mas sim sobre o consentimento e a comunhão arquetipica das almas."

Gilbert Durand

Procurando por uma pedagogia do imaginário, o presente artigo se constrói para se realizar enquanto um humilde esforço ainda enquanto uma aproximação entre estudos de arquetipologia ${ }^{2}$ e a educação. Entende-se que mais importante do que procurar responder às inúmeras angústias de nosso tempo, é o re-conhecimento de si, da própria cultura e da própria humanidade enquanto espécie do/no mundo. Para tanto, a arquetipologia durandiana se mostra como um importante guia para essa tarefa.

Hoje, para uma elite cultivada, as belas-artes, e para as massas, a imprensa, os folhetins ilustrados e o cinema veiculam o inalienável repertório de toda a fantástica. Por isso, é necessário desejar que uma pedagogia venha esclarecer, senão ajudar, esta irreprimível sede de imagens e sonhos (DURAND, 2002, p. 431).

O filósofo Gaston Bachelard, mestre de Durand, trouxe uma ampla perspectiva sobre o lugar da escola na sociedade. Para ele, "não é a Escola que deve ser feita à imagem da Vida, mas a Vida que deve ser feita à imagem da escola" (BACHELARD apud ROCHA, 2019). Esta é, ou deve ser, um modelo de sociedade. Entende-se esse olhar como uma tentativa de realocar a pedagogia à serviço do futuro, pelo presente. Pensar com Bachelard aqui quer dizer "olhar para a próxima geração", ou melhor, olhar para a vontade de perenidade, pelo nosso simples instinto de esperança e eternidade. É essa a justa perspectiva de qualquer princípio de socialidade.

É contra o nada do tempo que se levanta toda representação, e especialmente a representação em toda a sua pureza de antidestino: a função fantástica de que a

\footnotetext{
2 A arquetipologia procura organizar as imagens e os símbolos produzidos e/ou re-conhecidos pela imaginação humana em núcelos por meio do que Gilbert Durand chamou de "método de convergência", ou seja, constelando por semelhanças.
} 
memória não é mais que um incidente. A vocação do espírito é insubordinação à existência e à morte e a função fantástica manifesta-se como o padrão dessa revolta (DURAND, 2002, p. 403).

Toda representação busca, assim, por uma continuidade, no sentido do existir. A humanidade cria, em várias instâncias, de várias formas, para assegurar a sua existência diante do tempo. Vale ressaltar que aqui se fala de toda a espécie humana, de todas as culturas. A vontade é para a eternidade, vertical. Portanto, essa arquetipologia mostra o humano como simplesmente humano, seja ele em uma imaginação do tipo mais claro e científico possível, seja ele em uma imaginação do tipo mais místico e poético, seja ele em uma imaginação sintética.

Segundo Durand, a função da imaginação, no geral, se mostra como um grande "erguer-se contra tempo". O presente artigo, portanto, apresenta muito brevemente a teoria das estruturas antropológicas do imaginário, as quais o antropólogo francês sistematizou sob os "regimes de imagem". Para tanto, inIcialmente serão afastados "erros" comuns que buscam pré-determinar o ser humano em tipologia. Posteriormente serão apresentados o pressuposto da arquetipologia, a universalidade dos arquétipos, e os já mencionados regimes de imagem. E por fim, algumas considerações parciais são tecidas a fim de promover reflexões acerca das possibilidades de a educação se apropriar das valorizações positivas de tal corrente do pensamento.

\section{ATIPICALIDADE: NÃO HÁ PRÉ-DETERMINAÇÕES}

"[...] a imaginação bumana parece virgem de qualquer predeterminação categorial, e se pode falar, para além das intimações do caráter ou do sexo, de uma universalidade do imaginário que apenas a exceção patológica vem desmentir, na qual a imaginação parece bloqueada nesta ou naquela estrutura exclusiva".

Gilbert Durand

Se faz necessário para início de estudos sobre o imaginário, sublinhar o que as filosofias existencialistas nos possibilitaram: enxergar o ser humano como responsável por sua existência. Aqui, no entanto, não se quer adentrar no tema, que envolveria longas questões como liberdade, escolha, vontade, entre outras. Apenas se quer trazer à reflexão essa cautela: a arquetipologia não é 
uma tipologia que pré-determina a espécie, uma sociedade ou uma pessoa. Ao contrário, tais estudos reconhecem, pela função fantástica (a imaginação), o caráter criador do ser humano.

Acredita-se, como o psicólogo Carl Gustav Jung nos elucida, que o viver é em si um processo criativo. Vive-se pela criação. "O artista não cria como vive, mas vive como cria" (LESCURE apud BACHELARD, 2003, p. 17) Ou ainda como nos diz Michel Serres (2003, p. 12), "o sentido surge da função dinâmica, vital e coletiva da morte".

Assim, a tão humana função da imaginação faz com que o ser crie sobre o mundo: "As imagens imaginadas são antes sublimações dos arquétipos do que reproduções da realidade" (BACHELARD, 2001, p. 3). Imaginar, dessa forma, não é reproduzir o que o ser já viveu, as suas experiências. Mas criar, deformar, subverter, movimentar, escoar a existência, expandir as formas, tornar possível o impossível. "[...] foi na alegria, não na penúria, que o homem encontrou seu espírito. A conquista do supérfluo produz uma excitação espiritual maior que a conquista do necessário. O homem é uma criação do desejo, não uma criação da necessidade" (BACHELARD, 1994, p. 25).

Em toda ação há consciência, há portanto imaginação, um deformar de imagens. Cumpre às nossas investigações olhar mais e mais a fundo - a imagem pela imagem, como nos ensina Bachelard - para o conhecimento do funcionamento da própria consciência. Ferramentas como a fenomenologia, a hermenêutica, a mitanálise e a mitocrítica e a arquetipologia são conquistas recentes para a epistemologia. Se a intenção antes era a de se chegar a um método único e seguro, como quis a epistemologia cartesiana, por exemplo, os movimentos do final do século XIX e do século XX irão provocar uma abertura na filosofia das ciências, e o "novo espírito científico" (Bachelard), propondo o "não" como postura fundamental, irá propor à epistemologia a sua constante reformulação: a ciência não pode ser um saber absoluto. E é com isso que se poderá considerar outras ferramentas (como as já citadas) como possibilidades válidas para o conhecimento.

Dado que se pode notar uma imensa desvalorização do imaginário e de tudo o que mais se aproxima a ele, como a poesia, as artes, a mitologia e tais “outras ferramentas", é preciso um esforço para alocar no currículo e no interesse da pedagogia dominante ainda essas possibilidades. Uma vez que, como Jung notou em sua obra "O homem e seus símbolos", a consciência é uma conquista recente da espécie humana, pode-se perceber um hiato que diz respeito ao conhecimento dessa, cujo sobrevive por resistências, como pelos movimentos do romantismo, do surrealismo e da psicanálise, por exemplo. 
O que se pretende aqui é atentar para métodos que sejam mais capazes de dar conta desse conhecimento das produções imagéticas do humano. Bachelard reconhecia o quanto a filosofia é capaz de amadurecer o ser, no entanto alertava justamente para esse perigo de acelerar tal desenvolvimento. Para ele, era necessário "desamadurecer":

A filosofia amadurece-nos com muita rapidez e nos cristaliza num estado de maturidade. Como, então, sem se "desfilosofar", esperar viver os abalos que o ser recebe das imagens novas, das imagens que são sempre fenômenos da juventude do ser? Quando se está na idade de imaginar, não se sabe dizer como e por que se imagina. Quando se pode dizer como se imagina, já não se imagina. Seria preciso, então, desamadurecer (BACHELARD, 2003, p. 239).

Assim reconhece-se a necessidade de exercícios simples de ingenuidade, como sugere a própria fenomenologia bachelardiana, para se poder olhar para o ser sem julgamento, sem rotulações, sem pré-conceitos e, assim, sem um enquadramento em tipologias.

Os estudos de Gilbert Durand demonstram a fluidez da imaginação, o aspecto móvel do imaginário, que possibilita o movimento do ser e de toda a espécie enquanto sociedade(s). De um regime de imagens pode-se ir à outro. Não se vive sob um regime de imagens exclusivamente. No entanto, a dita "sociedade ocidental" vive majoritariamente sob a imaginação simbólica diurna, desde os esforços da filosofia platônica, cuja se intensificou na idade média com o neoplatonismo, o tomismo (aristotélico) e as tentativas de justificar a fé pela razão. O que se vê hoje ainda, portanto, é um ponto extremo do imaginário diurno. A sede de imagens que o humano sentiu e ainda sente, hoje está sendo "resolvida" pelas neopentecostais e todas as suas imagens: reis, moralismo, negação total do feminino e seus valores, a restauração do pecado, entre outras imagens/forças.

Aos estudiosos do imaginário, cumpre divulgar com cautela uma arquetipologia. O humano vive pela imagem. A negação desse princípio leva à mais alta necessidade de imagem. É pela via simbólica que a comunicação profunda se dá. E esse conhecimento deve e pode chegar à Educação desde os primeiros anos de vida.

Não há um determinismo (fatalista) biológico, de gênero, nem tampouco histórico ou social. Há forças, de um ambiente, contra (ou a favor) o sujeito - que é sujeito como um todo! Sendo assim, nem nossos estudos não devem servir à classificações das atividades humanas. Olhase para as imagens a fim de que elas se mostrem como portadoras de sentido. Um símbolo existe pela nossa (in)capacidade de comunicação, que vai muito além do dito. Um símbolo dá sentido. É ele o portador de um significado que escapa aos mecanismos da razão. Quando se olha para o 
simbólico, nunca se capta uma totalidade. Por isso as imagens são sempre forças, ambivalentes, por vezes paradoxais, cujas realizam-se enquanto movimentos transcendentais.

O mundo, o tempo, o real, vão sendo dialetizados e descobertos aos poucos pelo ser. Os sentidos se mostram nas fronteiras entre o psíquico imaginário e aquilo que denominamos matéria. Como nos diz ainda Gandhy Piorski (2016, p. 106), “os brinquedos da terra são a primeira soleira da consciência, a porta da cultura, o porto, o desembarque do trajeto antropológico - do reino imaginal para o reino espaço-temporal". É no germe do lento despertar da consciência que aqui se quer colocar a lupa de altas tecnologias filosóficas de pesquisa. Acredita-se no potencial da Educação e (sempre) dos educadores enquanto agentes dessa lenta condução à realidade - a função do pedagogo - por uma epistemologia (ou mais de uma) que permita cada ser a encontrar o seu caminho, a sua jornada heróica, uma vez que essa possui um caráter transpessoal, como nos diz James Hollis:

O mitologema do herói é uma personificação da energia necessária para servir à agenda transpessoal da vida, especialmente suas sequências desenvolvimentistas. Somos trazidos aqui, e todas as células do nosso corpo sabem disso, para tornarmo-nos, para florescer, para florir (HOLLIS, 2015, p. 71).

Cada jornada é, assim, uma forma de responder não só a um desejo pessoal, mas transpessoal, coletivo. E o trabalho, expressão legítima de uma vontade de potência - chamado por Bachelard de vontade de trabalbo -, é sempre uma manifestação de algo que uma comunidade, uma sociedade e um cosmos todo precisam.

\section{ARQUÉTIPOS: FORMAS UNIVERSAIS}

"[...] a alma contém todas as imagens das quais surgiram os mitos, [...] nosso inconsciente é um sujeito atuante e padecente, cujo drama o homem primitivo encontra analogicamente em todos os fenômenos grandes e pequenos da natureza."

Carl Gustav Jung 
Pensar as imagens da espécie, eis a filosofia do imaginário. Contudo, não é fácil discorrer sobre um campo tão incerto. A tarefa da razão, do logos pelo qual o imaginário ocidental se construiu e atua em nossa época (o reino do arquétipo do animus), é em direção oposta: à luz. Desde A Alegoria da Caverna de Platão encontra-se a sede pelo divino, pela (pretensa) pureza do mundo dos conceitos. É claro que não sem encontrar resistências. Nietzsche notara a co-substancialidade entre o apolíneo e o dionisíaco, entre dia e noite. Gilbert Durand nos dirá que o dia é que atua como antítese ainda.

Semanticamente falando, pode-se dizer que não há luz sem trevas enquanto o inverso não é verdadeiro: a noite tem uma existência simbólica autônoma. $\mathrm{O}$ regime diurno da imagem define-se, portanto, de uma maneira geral, como o regime da antítese (DURAND, 2002, p. 67).

Diante disso, acredita-se que à Educação deva ser entregue possibilidades de pesquisa com base em tais estudos. Práticas imagéticas no geral, artes, literatura, além do mais, são agora fontes que revelam as profundezas da psique. De certo modo, já admite-se a realidade do irreal, a sua funcionalidade. A abertura ao lado onírico da existência para estudos mais ou menos sistematizados foi uma das grandes conquistas da psicanálise - ainda com Freud. Porém, enquanto portadora de uma metodologia que possibilite um encontro um tanto mais seguro com as imagens - uma ciência das imagens -, foi com Jung que se pode dizer haver um melhor aprofundamento, fazendo com que Durand denomine a hermenêutica de Jung como instauradora, enquanto que a de Freud como redutora - uma vez que esse "reduzia" o que era visto ao seu método.

[...] se Freud tinha uma concepção muito apertada do simbolismo, que reduzia a uma causalidade sexual, podemos dizer que Jung tem uma concepção demasiado ampla da imaginação simbólica, que só concebe na sua atividade sintética - isto é, na sua atividade mais normal, mais ética - não tendo praticamente em conta o "carater mórbido" de certos símbolos, de certas imagens (DURAND, 1995, p. 60).

Com Bachelard, uma hermenêutica instauradora dará seguimento e com Durand se abrirá para as possibilidades da Mitanálise. Movimentos todos do século XX ainda. E que acredita-se que suas potencialidades possam (e até devam) ecoar para a Educação, para uma Pedagogia do Imaginário. 
[...] se esta pedagogia tem a sua justificação na função eufêmica da imaginação, também não pode descartar a sua responsabilidade de mediação, de equilíbrio (biológico, psíquico, sociológico e remitologizador) e de apelo no tocante às restantes funções da imaginação simbólica: a função psico-social (realização simbólica e reequilíbrio social), a função humanista (o ecumenismo do símbolo) e a função teofânica (a grande obra dialéctica) (ARAÚJO; TEIXEIRA, 2009).

Tais instrumentos possibilitam aos educadores criar práticas que possam contribuir com o auto-conhecimento dos estudantes. Encontros com atividades fundamentadas no mitológico revelam aos próprios estudantes imagens que lhes sirvam de "guias", "conselhos", "sugestões", sem o tão habitual aconselhamento moralista oriundo das culturas patriarcais, onde reina a mentalidade colonizadora de uma ontologia totalizante. O simbólico, por sua semântica criadora, é uma pedagogia de possibilidades. "[...] o mito nunca é uma notação que se traduza ou se decodifique, mas é sim presença semântica e, formado de símbolos, contém compreensivamente o seu próprio sentido" (DURAND, 2002, p. 357).

Cumpre assim o conhecimento da arquetipologia à Educação enquanto um componente de base, para uma pedagogia de libertação do domínio das estruturas esquizomorfas (e colonizantes) do regime reinante de imagens (o diurno). E ainda: uma vez que, como demonstraram Jung e Durand, os arquétipos se mostram universais, é possível fazer de tais estudos uma importante ferramenta, cuja pode-se aplicar a inúmeros contextos e a dar uma vazão mais saudável às pulsões imaginárias da humanidade.

\section{O REGIME DIURNO: UMA JORNADA À CIÊNCIA}

Como já foi mencionando, vive-se atualmente no reino do regime diurno das imagens. Cabe então conhecer as forças que motivam seu reinado, uma vez que, como bem sabia Jung, aquilo que desconhecemos e negamos em nós, volta como fantasma ou destino. Os arquétipos e os símbolos diurnos precisam ser reconhecidos antes ainda enquanto produtos da imaginação, assim como as imagens noturnas já o são. Como nos traz Durand (2002, p. 41), "no homem, como todas as informações são controladas pelo "terceiro cérebro" (ou "cérebro noemático") (P. Chauchard), elas passam a ser indiretas. Todo pensamento humano é uma re-presentação, isto é, passa por articulações simbólicas”. 
Como Bachelard alertava, a imprudência é um fator importante para a criação, para o novo. É preciso arriscar-se. Ontologicamente, o filósofo preferia a criação ao hábito, a força à inércia, a vida à morte. Sendo assim, aqui arrisca-se a pensar o regime diurno das imagens enquanto um repositório das forças que impulsionam o ser ao real, à ciência. À frente se explicará também a valorização do irreal. Mas por ora se investirá no real.

A luz é uma conquista humana, ou sobre-humana, divina? Tanto se por um investimento dos deuses que cederam a luz à humanidade ou se por uma conquista oriunda do desbravamento das trevas do mundo caótico, a luz é o caminho para a diferenciação do homem dos outros animais. No budismo se dirá que o nascimento humano é precioso, é um privilégio, justamente pela possibilidade de liberdade.

A luz é para ver melhor, obviamente. Ver para saber. O olho é o órgão predileto do conhecimento científico. Por muito tempo se duvidou dos sentidos enquanto fontes seguras. A visão, no entanto, sempre foi a menos duvidosa: é preciso ver para crer, dirá a sabedoria popular. É a estrutura, enquanto força motivadora, dinamizadora do psiquismo, dessa forma de ver o mundo que aqui se busca para se provocar uma pedagogia da epistemologia dos próprios estudantes. A intenção é a de chegar ao estudante, com imagens que abrem caminhos, para que esse busque (em si e/ou no mundo) a sua epistemologia.

De fato, a objetividade científica só é possível se inicialmente rompemos com o objeto imediato, se recusamos a sedução da primeira escolha, se detemos e refutamos os pensamentos que nascem da primeira observação. Toda objetividade, devidamente verificada, desmente o primeiro contato com o objeto. Ela deve, em primeiro lugar, criticar tudo: a sensação, o senso comum, inclusive a prática mais constante, e finalmente a etimologia, pois o verbo, feito para cantar e seduzir, raramente coincide com o pensamento (BACHELARD, 1994, p.2).

Arma-se de inteligência, empunha-se o óculos de visionário, assim vai se construindo o novo herói: o cientista. Não que as demais jornadas sejam menos importantes. Pelo contrário, ao se re-conhecer os caminhos do heroísmo, se percebe um movimento também de descida. Portanto, a caminho das luzes da ciência, deve-se perceber aquilo que Bachelard denominou de filosofia do não. Essa atitude epistemológica é justamente a recusa do espírito diante das imagens primeiras, do mundo. A ciência se faz por um processo dialético, contínuo ou descontínuo, caminha. Assim 
como o herói, que mesmo impulsionado por forças imagéticas da alma, recusa as trevas e combate a cegueira e a podridão da ignorância. As imagens da ciência são conquistas de um heroísmo; não se faz ciência sem o processo antitético do imaginário heróico.

\section{O REGIME NOTURNO MÍSTICO: UM REPOUSO NO MUNDO}

Os arquétipos e símbolos do regime noturno da imagem são formados por um processo de inversão de valores ou de um duplo negativo da noite. As imagens estão ligadas à psique por um eufemismo que aceita a tudo. Tudo vem das trevas e tudo volta a elas. Tudo vem da Mãe-Terra e voltará à Mãe-Terra. Se nasce da mãe e se quer buscar esse repouso de alguma forma no mundo. Por isso Durand nos fala no simbolismo da "taça", um símbolo de continente, que contém o ser, que acolhe, acomoda.

Se pode pensar em toda uma rede de valores oriundos desse regime: o acolhimento, o amor, o carinho, a empatia, a alteridade. A partir da noite se pode pensar inúmeras pedagogias, que tenham como fim um auto-conhecimento, da própria anima. Antes do que um pensar sobre vontades, pela noite se pensam os repousos, os refúgios, as grutas, os acalantos da alma, o que nos coloca em situação de paz, o nosso berço.

De fato, a gruta é um refúgio no qual se sonha sem cessar. Ela confere um sentido imediato ao sonho de um repouso protegido, de um repouso tranquilo. Passado um certo limiar de mistério e pavor, o sonhador que entrou na caverna sente que poderia morar ali. Bastam uns poucos minutos de permanência para que a imaginação comece a ajeitar a casa (BACHELARD, 2003, p. 143).

Enquanto o herói procura por uma ascensão, no imaginário noturno não se tem medo da queda, se quer justamente descer, lentamente, para se reconhecer enquanto cada degrau - tudo no sonho é o próprio sonhador. É sobre o conhecimento (e, mais ainda, a aceitação) da intimidade que aqui se discorre. Um saber cujo "ocidente" tem um certo medo. Ou como Jung (2016, p. 23) nos diz: 
Quem quer que negue a existência do inconsciente está, de fato, admitindo que hoje em dia temos um conhecimento total da psique. É uma suposição evidentemente tão falsa quanto a pretensão de que sabemos tudo a respeito do universo físico. Nossa psique faz parte da natureza, e o seu enigma é, igualmente, sem limites. Assim, não podemos definir nem a psique nem a natureza. Podemos, simplesmente, constatar o que acreditamos que elas sejam e descrever, da melhor maneira possível, como funcionam. No entanto, fora de observações acumuladas em pesquisas médicas, temos argumentos lógicos de bastante peso para rejeitarmos afirmações como "não existe inconsciente". Os que fazem este tipo de declaração estão expressando um velho misoneísmo - o medo do que é novo e desconhecido.

Bachelard nos traz ainda uma boa imagem que Jung utiliza: "A consciência comporta-se então como um homem que, ouvindo um ruído suspeito no porão, precipita-se para o sótão para constatar que lá não há ladrões e que, por conseguinte, o ruído era pura imaginação. Na realidade, esse homem prudente não ousou aventurar-se no porão” (JUNG apud BACHELARD, 2003, p. 37). Tal exemplo ilustra o imaginário "ocidental", uma vez que o combate diurno que esse levou e ainda leva até as últimas consequências possa se caracterizar facilmente como uma estrutura esquizóide, que não consegue aceitar a realidade, movente e intuitiva.

Talvez se possa dizer que se deve às conquistas da Psicologia o reconhecimento de um mundo um tanto menos abstrato para o Ocidente. Enquanto no Oriente pode-se encontrar facilmente símbolos muito sofisticados representando e significando profundos processos psíquicos - como o budismo o faz -, ao Ocidente imaginar ainda é uma "fraqueza", um "erro". Preocupa-se mais com os valores sociais e abstratos de um produto artístico do que com os valores psicológicos de uma obra de arte. A Arteterapia é uma área, por exemplo, que ainda tem muito por desbravar diante de um cenário cada vez mais monárquico.

“O regresso imaginário é sempre um 'ingresso' mais ou menos cenestésico ou visceral" (DURAND, 2002, p. 201). A descida deve ser lenta, portanto. Nas profundezas estão nossas fragilidades, está a nossa maciez, e as guardamos em um espaço acolhedor, afetivo, por isso quente.

O calor interioriza-se, concentra-se, oculta-se. Mais precisamente que o fogo, é o calor que merece o nome de a terceira dimensão $[. .$.$] O interior sonhado é cálido,$ jamais ardente. O calor sonhado é sempre suave, constante, regular. Pelo calor, tudo é profundo. O calor é o signo de uma profundidade, o sentido de uma profundidade (BACHELARD, 2003, p. 40). 
À noite se ama. O mundo, o cosmos, o macro, o micro, a carne, o corpo, a terra. A imaginação telúrica, tão bem estudada por Bachelard, irá nos revelar esse bem-estar, o nosso ser e será ainda um espelho energético, podendo possibilitar até estudos de caracterologia ${ }^{3}$. O pancalismo bachelardiano está envolto de uma poética ímpar, há um acolhimento do mundo e do ser. "Quem olha para fora sonha. Quem olha para dentro desperta", nos diz a famosa frase de Jung. O que nos importa aqui é menos um sentido que nos dirá se trata-se de Jung estar certo ou errado do que o próprio sentido de inversão antes mencionado. Assim se fará o repertório simbólico da noite: invertendo possibilidades. Os mais “esclarecidos” poderão perguntar: “como é possível despertar olhando para dentro?” E poder-se-ia responder com Novallis (apud DURAND, 2002, p. 209): "toda a descida dentro de si é ao mesmo tempo assunção para a realidade exterior."

\section{O REGIME NOTURNO RÍTMICO: VENCENDO O TEMPO}

Enquanto que no regime diurno nota-se o herói e no regime noturno místico a intimidade, o ideal representante do regime noturno rítmico é a música, dada a sua propriedade de harmonizar vozes, ritmos, narrativas. Serão encontrados verbos como, além de harmonizar, dialetizar e contrastar, caracterizando assim um imaginário dramático, ou seja, uma imaginação que tensiona e resolve, que procura por um pulso, cosmológico ou até cosmogônico. Trata-se, portanto, de uma busca pelas sínteses, onde de um lado há a "repetição infinita de ritmos temporais" e de outro há um "interesse para o papel genético e progressista do devir" (Durand). O “eterno retorno" em contraste com o "progresso".

As duas categorias destes símbolos que se enlaçam ao tempo para o vencer vão ter como caráter como o serem mais ou menos "histórias", "narrativas", cuja principal realidade é subjetiva e a que se costuma chamar "mitos". [...] Estes mitos, com a sua fase trágica e a sua fase triunfante, serão assim sempre dramáticos, quer dizer, porão alternativamente em jogo as valorizações negativas e positivas das imagens. Os esquemas cíclicos e progressistas implicam assim quase sempre o conteúdo de um mito dramático (DURAND, 2002, p. 282).

\footnotetext{
3 A caracterologia é o estudo da relação entre o ser e o mundo, a capacidade de adaptação, assimilação ou subversão de uma cultura, de uma sociedade. Difere-se, portanto, tanto do conceito de temperamento quanto de personalidade.
}

Cadernos Cajuína, V. 6, N. 1, 2021, p. 310-325. 
Essas sínteses têm a sua grande manifestação no calendário, no "ano", que marcará o fim e o início de um novo drama astral a ser repetido. A intenção imaginária de domínio do tempo aqui está presente na sua espacificação.

Os rituais repetirão assim cosmogonias, desde a dramatização do início dos tempos manifesta nas festas em que se celebra o caos primordial, como o próprio réveillon. E a primeira representante a marcar os tempos será a lua, muito provavelmente pelo número de suas fases, que são quatro e que ajudarão culturas inteiras a se guiarem, como, por exemplo, na fundação do calendário gregoriano e sua divisão duodecimal (três vezes o quatro), ou, inclusive, na agricultura, onde, primitivamente e ainda pelos poderes imaginativos, irá se sobrepor até às marcações solares e sazonais no plantio. Há, portanto, o diálogo do dia e da noite, do Natal solar e da Páscoa lunar, do sol e da lua na construção de calendários.

O simbolismo lunar reunirá ainda as mais ricas histórias e dramas cósmicos, astrais, nas mais variadas religiões e culturas. "As personagens do drama astral não passam de microcosmos míticos do drama epifânico da lua" (DURAND, 2002, p. 290). A lua é a “mãe do plural” (Durand), reúne sob si as mais diversas imagens, as mais diversas noções de divindade, de abundância. Tétrades e tríades divinas poderão, por exemplo, ser condensadas sob a dialética, sob a síntese proposta pelo seu simbolismo. Sendo assim, a lua aparece como um dos símbolos mais marcantes. Toda uma herança das culturas mais agrícolas está em nossos marcos no calendário, em nossas sensibilidades conectadas ao tempo lunar. A lua, por suas sugestões de lentidão, de ciclos, de renascimento, irá marcar os “tempos mais sensíveis” (Mircea Eliade).

É evidentemente o fenômeno natural com as fases mais marcadas e o ciclo suficientemente longo e regular que vai, em primeiro lugar, tornar-se o símbolo concreto da repetição temporal, do caráter cíclico do ano. A lua aparece, com efeito, como a primeira medida do tempo. A etimologia da lua é, nas línguas indoeuropeias e semitas, uma série de variações sobre as raízes linguísticas significativas da medida. [...] Não só a etimologia como também os sistemas métricos arcaicos provam que a lua é o arquétipo da mensuração (DURAND, 2002, p. 285).

Por um lado, seu simbolismo não será polêmico, antitético, diairético como o do herói, como quer a imaginação diurna. Por outro, não carregará as confusões místicas. A lua é morte e renovação, é vida e marca nessa imaginação a vitória sobre o tempo. Como sua simbologia é sintética, conservando os valores da vida e da morte, a lua é também hermafrodita, conserva o dia e a noite. 
No imaginário sintético existem ainda símbolos como a árvore, cuja aponta para cima e é a "promessa dramática do cetro." (Durand), o filho e o andrógino.

O símbolo do Filho seria uma tradução tardia do androginato primitivo das divindades lunares. O Filho conserva a valência masculina ao lado da feminilidade da mãe celeste. Sob a pressão dos cultos solares, a feminilidade da lua ter-se-ia acentuado e perdido o androginato primitivo de que apenas uma parte é conservada na filiação (DURAND, 2002, p. 300).

O filho é a mistura, o movimento, a continuação, a repetição dos pais, o messianismo, o próprio devir. Une e resolve o masculino e o feminino, o dia e a noite. É assim andrógino e dará movimento à vida, sendo a própria manifestação do devir temporal, porém também humano. Tem a capacidade de ir aos dois (ou mais) mundos. Como Cristo ou Hermes Trismegisto, personagens que narram dramas essencialmente andróginos.

Poder-se-ia elencar ainda outros símbolos que nos ajudam a compreender mais e melhor do imaginário sintético. Entretanto, acredita-se aqui que com esses elementos já se pode ter uma boa noção do seu funcionamento.

\section{CONSIDERAÇÕES FINAIS}

Após uma breve elucidação da teoria do imaginário do antropólogo Gilbert Durand, trazendo importantes contribuições da psicologia de Jung e da filosofia de Bachelard, acredita-se que se pode provocar os estudiosos da Educação, das pedagogias, a se abrirem à proposta de pedagogias plurais do imaginário. Instâncias mais abertas, mais humildes, mais sinceras, mais ingênuas, se fazem necessárias para acolher as tantas possibilidades que as diversas pedagogias encontradas nos estudos desses (e outros) pensadores possuem.

Sem dúvida, não se deve negar as conquistas do espírito científico, e muito menos do "novo espírito científico" (Bachelard). A “cidade científica” proposta pelo filósofo ainda pode ser um

\footnotetext{
$4 \quad$ O cetro é um símbolo verticalizante usado por Durand para representar a intenção ascensional da imaginação.
} 
ideal que pode nos mover, verticalmente. Por outro lado, dado que, como foi trazido no texto, há uma predominância do regime diurno da imagem neste momento - e talvez mais ainda na reação dos últimos anos que sufocam as ciências humanas, as artes e poesia como um todo -, talvez se faça mais necessária uma valoração positiva do lado noturno do mundo, da cultura, das comunidades, da alma. É o que Nietzsche, ainda no século XIX, já havia percebido quando chamava por uma valoração da vida e da morte, da renovação, da felicidade, da carne, da poesia, em contraposição a uma dominância do que é apolíneo.

Teorias feministas, olhares revolucionários, pulsões que movem almas à movimentos sociais intensos pelo mundo, ideologias anti-capitalistas, há uma enorme vontade de feminizar o mundo, de "noturnizá-lo". Talvez se faça necessário seguir. Não afrouxar diante do reacionarismo crescente, no Brasil e em muitas outras partes do mundo.

À Educação poderá competir tomar posse de poéticas libertadoras. Não só se justificando aos olhares das ciências naturais, mas se mostrando como se é. Afinal, o devaneio atua por uma via diferente, como bem mostrou Bachelard. E, apesar da pouca força, há muitos movimentos que já atuam em prol de um olhar poético para a(s) infância(s).

“A pedagogia Waldorf, nos anos 1920, com Rudolf Steiner" abre "uma ciência das imagens, propõe-se nutrir o alargamento do ser pela imaginação" (PIORSKI, 2016, p. 40). Com sua antroposofia, com suas observações acerca da relação entre o ser humano e o cosmos, Steiner possibilita toda uma pedagogia, por exemplo, do sensível (poética), cuja vê na criança de até 7 anos (no primeiro setênio) um ser materialista, animista e que necessita apreender o mundo por via dos sentidos, da imitação, pelo bem-estar, pela imaginação. Traços que, inclusive, se ligam às concepções, de certa forma, pedagógicas de Bachelard a respeito da criança, como nos mostram Rocha, Santos e Pinho (2019):

Steiner acredita que quando a criança nasce está em um estado de consciência resumida ao que acontece ao seu redor. As crianças começam as interações com o meio repetindo o que os adultos fazem, um dos primeiros sentimentos a ser trabalhado é o da segurança, desde o bem-estar familiar, até na escola onde entrará em contato com jardins, árvores, balanços. Steiner considera que nesses primeiros anos de vida a criança deve ter contato com brinquedos feitos à base de madeira e argila, por serem elementos vivos.

O pensamento de Paulo Freire com suas pedagogias, por onde se procura pelas vozes mais marginalizadas, permitindo-lhes uma dignidade perante circunstâncias tão opressoras, sem as 
intenções colonizantes tão comuns às ontologias totalizantes do pensamento educacional dito tradicional, pode ser considerado outra perspectiva importante para se trabalhar por uma pedagogia do imaginário. Pode-se olhar ainda para os trabalhos de Loris Malaguzzi e a sua abertura às/pelas conhecidas "cem linguagens" da criança, assim como para as contribuições de Rubem Alves em suas famosas crônicas reflexivas, sensíveis, e o seu profundo desejo de uma educação romântica, que valorize a poética e o maravilhamento do ser e de toda a educação.

Caso queira-se procurar, seriam encontrados ainda muitos outros importantes trabalhos realizados desde as pequenas cidades de interior às grandes metrópoles. O que aqui se quer é refletir acerca de uma postura humilde no re-conhecimento de uma necessidade de se trabalhar para se conhecer o homem, a si mesmo, as culturas, o mundo, o imaginário, de uma forma para que não haja a visão de que uma cultura seja superior à outra, nem de que uma epistemologia seja superior à outra, mas sim num sentido de comunhão.

\section{REFERÊNCIAS}

ARAÚJO, Alberto Filipe; TEIXEIRA, Maria Cecília Sanchez. Gilbert Durand e a pedagogia do imaginário. Letras de Hoje, Porto Alegre, v. 44, n. 4, p. 7-13, out. 2009.

BACHELARD, Gaston. A poética do espaço. São Paulo: Martins Fontes, 2003.

A psicanálise do fogo. São Paulo: Martins Fontes, 1994.

A terra e os devaneios da vontade: ensaio sobre a imaginação das forças. São Paulo: Martins Fontes, 2001.

A terra e os devaneios do repouso: ensaio sobre as imagens da intimidade. São Paulo: Martins Fontes, 2003.

BARBOSA, Eliana; BULCÃO, Marly. Bachelard: pedagogia da razão, pedagogia da imaginação. Petrópolis: Vozes, 2004.

DURAND, Gilbert. A imaginação simbólica. Lisboa: Edições 70, 1995.

Cadernos Cajuína, V. 6, N. 1, 2021, p. 310-325. 
As estruturas antropológicas do imaginário: introdução à arquetipologia geral. São Paulo: Martins Fontes, 2002.

. O imaginário: ensaio acerca das ciências e da filosofia da imagem. Rio de Janeiro: DIFEL, 2004.

HOLLIS, James. Mitologemas: encarnações do mundo invisível. São Paulo: Paulus, 2015.

JUNG, Carl Gustav. O homem e seus símbolos. Rio de Janeiro: Harper Collins, 2017.

Os arquétipos e o inconsciente coletivo. Rio de Janeiro: Vozes, 2000.

PIORSKI, Gandhy. Brinquedos do chão: a natureza, o imaginário e o brincar. São Paulo: Peirópolis, 2016.

ROCHA, Gabriel Kafure da; SANTOS, Débora Maria dos; PINHO, Ronald Oliveira. A infância em Bachelard e Steiner: um ponto de vista da educação antroposófica contra a crítica de Onfray. Interação: Revista de Ensino, Pesquisa e Extensão, Varginha, v. 21, n. 1, p. 51-67, nov. 2019.

SERRES, Michel. Hominescências: O começo de uma outra humanidade? Rio de Janeiro: Bertrand Brasil, 2003. 